\title{
CONSIDERATIONS ON TECHNICAL EQUIPMENT USED FOR CLEANING AND SORTING SEED MIXTURES BASED ON AERODYNAMIC PRINCIPLE
}

\author{
Carmen Bracacescu, Paul Gageanu, George Bunduchi, Alexandru Zaica \\ National Institute of Research-Development for Machines and Installations Designed to Agriculture \\ and Food Industry, Romania \\ carmenbraca@yahoo.com,paulgageanu@yahoo.com, georgebund@yahoo.com, \\ zaica_alexandru@yahoo.com
}

\begin{abstract}
The foreign bodies located in the grain mass have physical and morphological properties that distinguish them from the basic culture, and which are used in manufacturing the separating equipment. The experts' attention has been drawn by the study of phenomena, which influence the process of separating impurities, aiming at a maximum reduction of impurities from the grain matter. Cereal and industrial plant seed pre-cleaning and cleaning, prior to their storage or processing, is a complex technological process that includes a multitude of constructive types for technical equipment designed to separate and remove existing impurities in the seed mass, which are based on various separation principles. Impurities in the seed mass are also different from the main crop seeds (grain seeds or industrial plants) in terms of aerodynamic properties. This paper presents some theoretical aspects regarding the separation of seed mixtures based on the aerodynamic principle (resistance of the seed mass layer to the passage of air, seed floating capacity, air stream working velocities, total air flow rate), which were the basis for the development of a new type of aeration cleaning separator SCA 5 for seed mixtures cleaning and sorting. The advantages of using this equipment in the process of precleaning/cleaning cereal and industrial plant seeds are also mentioned.
\end{abstract}

Keywords: seeds, sorting, aerodynamic principle.

\section{Introduction}

Primary processing is an important link to the process of capitalizing plant origin products and is a primary operation of the conditioning chain. This is based on removing foreign bodies from the product mass, providing optimal processing dimensions, preventing or limiting chemical or biochemical processes during storage, leading to deterioration in quality and even the alteration of the plant material $[1 ; 2]$.

Taking into account these considerations, the attention of the specialized researches focused on the study of the phenomena that influence the process of separating the impurities, the aim being to minimize the impurities that reach the final processing stages of cereals [3-5].

Also, primary grain processing operations play a particularly important role in preparing the product for various future uses because:

- the percentage of impurities, seeds of some other crops, or pieces of the basic crop seeds, contained in the mass of agricultural products harvested with the combine reaches fairly high values;

- the processes of increasing the purity of agricultural products differ according to their nature and the destination they receive after harvesting (conservation, consumption, industrialization, marketing, sowing, etc.);

- these operations aim at eliminating impurities of any nature, creating better storage conditions, and reducing the volume of transport and storage [6-10].

In order to obtain the maximum quality with minimum energy and labour consumption a thorough knowledge is necessary of the technology used, the functioning of the technical equipment specific to the technology as well as the regulation of the technical and functional parameters of this equipment.

The paper presents several reference theoretical aspects regarding the separation of seed mixtures based on the aerodynamic principle, aspects that were underpinnings of elaborating an innovative technology to obtain seed material for the efficient establishment of agricultural cultures and designing a new type of aeration cleaning separator SCA 5, destined to cleaning and sorting seed mixtures. 


\section{Materials and methods}

Impurities in the seed mass are different from the main crop seeds (grain seeds or industrial plants) in terms of aerodynamic properties. These aerodynamic properties take into account the different movement resistances of seeds in an air stream.

In order to carry out the aerodynamic separation process of a mixture of solid particles (seeds in particular), we must take into account a number of factors, which have a major impact on the way of its development, among which [11-14]:

- the properties of solid particles subjected to aerodynamic separation;

- the properties of the air stream, respectively: the direction of the air stream and the flow regime;

- the way of making the biphasic gas-solid (G-S) mixture.

The resistance of the seed mass layer to the passage of air or gas is a property of particular interest in aeration, gas, drying, etc. processes.

The total resistance of the granular material layer to the passage of air or gas is calculated with the relation [3]:

$$
R=A \cdot h \cdot W^{n}, \mathrm{mmH}_{2} \mathrm{O}
$$

where $h$-thickness of the material layer, in m;

$W$ - conventional air or gas velocity relative to the entire section of the seed layer, $\mathrm{m} \cdot \mathrm{s}^{-1}$;

$A, n$-coefficients determined experimentally according to the characteristics of the seeds

Table 1 shows the resistance of $0.01 \mathrm{~m}$ seed layer for different air velocities and different cereals $[2 ; 3]$.

Table 1

Resistance values of $0.01 \mathrm{~m}$ seed layer for different cereals

\begin{tabular}{|c|c|c|c|c|c|c|c|c|c|}
\hline \multirow{2}{*}{ No. } & \multirow{2}{*}{ Cereal } & \multicolumn{6}{|c|}{ Coefficients value } & \multicolumn{5}{|c|}{ Seed layer resistance $\boldsymbol{R}, \mathbf{m m H}_{\mathbf{2}} \mathbf{O}$} \\
\cline { 3 - 10 } & & $\boldsymbol{A}$ & $\boldsymbol{n}$ & \multicolumn{4}{|c|}{} & \\
\hline 1 & wheat & 1.41 & 1.43 & 0.52 & 1.41 & 2.53 & 3.81 & 5.23 & 14.1 \\
\hline 2 & maize & 0.67 & 1.53 & 0.19 & 0.55 & 1.04 & 1.62 & 2.28 & 6.7 \\
\hline 3 & rye & 1.76 & 1.41 & 0.68 & 1.81 & 3.22 & 4.84 & 6.62 & 17.6 \\
\hline 4 & barley & 1.44 & 1.43 & 0.53 & 1.44 & 2.58 & 3.89 & 5.35 & 14.4 \\
\hline 5 & rice & 1.76 & 1.41 & 0.68 & 1.81 & 3.22 & 4.84 & 6.62 & 17.6 \\
\hline
\end{tabular}

In its turn, the seed floating capacity is defined by the air velocity for which the seeds in a vertical duct are in a steady state (floating) and is particularly important for the separation based on the difference in aerodynamic properties, for aspiration calculation, etc.

The floating velocity depends on the specific mass, surface condition, shape and geometric dimensions of the particles forming the components of the seed mixture.

Table 2 shows the aerodynamic characteristics of different cereals [2].

Table 2

Aerodynamic characteristics of different cereals

\begin{tabular}{|c|c|c|c|}
\hline \multirow{2}{*}{ Product } & \multicolumn{3}{|c|}{ Aerodynamic characteristics } \\
\cline { 2 - 4 } & $\begin{array}{c}\text { Specific mass, } \\
\mathbf{k g} \cdot \mathbf{~ m}^{-\mathbf{3}}\end{array}$ & $\begin{array}{c}\text { Aerodynamic } \\
\text { drag coefficient }\end{array}$ & $\begin{array}{c}\text { Floating velocity, } \\
\mathbf{m} \cdot \mathbf{s}^{-\mathbf{1}}\end{array}$ \\
\hline Wheat & $1.3-1.4$ & $0.18-0.26$ & $8.1-12.3$ \\
\hline Rye & $1.2-1.5$ & $0.16-0.22$ & $8.3-9.9$ \\
\hline Barley & $1.2-1.4$ & $0.19-0.27$ & $8.4-10.7$ \\
\hline Rice & $1.1-1.2$ & $0.19-0.26$ & $8.0-10.8$ \\
\hline Maize & $1.2-1.5$ & $0.16-0.24$ & $12.5-14.0$ \\
\hline Millet & $1.1-1.2$ & $0.04-0.07$ & $9.8-11.8$ \\
\hline
\end{tabular}


The air flow $\left(\mathrm{m}^{3} \cdot \mathrm{s}^{-1}\right)$ for processing a mixture with a mass flow rate of $1 \mathrm{~kg} \cdot \mathrm{s}^{-1}$ depends on the nature of the product and the purpose of the work being carried out.

For preliminary cleaning, the air flow can be determined with the relation $[2 ; 3]$ :

$$
Q_{a p}=k_{u} \cdot S_{c p} \cdot v_{a 1} .
$$

While for sorting, it is determined with the relation:

$$
Q_{a s}=k_{u} \cdot S_{c s} \cdot v_{a 2},
$$

where $k_{u}$ - uniformity coefficient of the air stream on the sieve; $k_{u}=0.65$;

$v_{a 1}$ and $v_{a 2}$ - air stream velocities in the two cases;

$S_{c p}$ and $S_{c s}$ - sections of channels for the transport of separated fractions that are determined by relations $[2 ; 3]$ :

$$
\begin{gathered}
S_{c p}=\frac{Q \cdot\left(100-q_{c p}\right)}{100 \cdot q_{s}}, \\
S_{c s}=\frac{Q \cdot\left(100-q_{c p}-q_{c s}\right)}{100 \cdot q_{s}},
\end{gathered}
$$

where $Q$ - feed flow rate of the installation;

$q_{c p}$ and $q_{c s}$ - flow rates of the fractions that must be removed;

$q_{s}$ - product specific feed rate for an installation that is supplied with an air flow rate of $1 \mathrm{~m}^{3} \cdot \mathrm{s}^{-1}$.

The total air flow rate $\left(\mathrm{m}^{3} \cdot \mathrm{s}^{-1}\right)$ required by the aeration cleaning separator can be determined by the relation $[2 ; 3]$ :

$$
Q_{a}=\sum_{i=1}^{n} Q_{s i}+\sum_{i=1}^{n} Q_{t i},
$$

where $Q_{s i}$ - air flow rate required for separation in step $i$ (for an installation with n separation steps);

$Q_{t i}$ - air flow rate required to transport the product from step $i$ to the next step.

The air streamworking velocities are chosen according to the aerodynamic characteristics of the mixture components, respectively the critical floating velocity of these components.

The determination of the total air flow $Q_{a}\left(\mathrm{~m}^{3} \cdot \mathrm{s}^{-1}\right)$ required for the separation and transport of a particle mixture depends on the specific feed rate $q_{s},\left(\mathrm{~kg} \cdot \mathrm{s}^{-1}\right)$ and the static pressure losses in the installation air ducts. Experimental data show that admissible loads can be considered those presented in Table 3.

Admissible load $q_{a}$ for different types of cereal seeds

Table 3

\begin{tabular}{|c|c|c|}
\hline \multirow{2}{*}{ Type } & \multicolumn{2}{|c|}{ Admissible load $\boldsymbol{q}_{\boldsymbol{a}}, \mathbf{k g} \cdot \mathbf{s}^{-1} \cdot \mathbf{m}^{\mathbf{2}}$} \\
\cline { 2 - 3 } & Pre-cleaning duct & Sorting duct \\
\hline Wheat & $3.5-4.0$ & $1.8-2.0$ \\
\hline Rye & $3.5-4.0$ & $1.8-2.0$ \\
\hline Oat & $2.5-3.0$ & $1.3-1.5$ \\
\hline Barley & $2.5-3.0$ & $1.3-1.5$ \\
\hline
\end{tabular}

The working capacity of a separation equipment takes into account the volume of the material separated in a given period of time, under the conditions of a directed medium feed flow rate and a use coefficient of the calculated working time, e.g. $k_{t}=0.7$.

\section{Results and discussion}

The proposed aeration cleaning separator SCA 5 (Figure1) designed by INMA is intended for seed cleaning and removal of all impurities (weed seeds, broken grains, plant debris, soil, dust, etc.) of the main product mass in order to be as pure as possible and for seed sorting, namely the division of 
the main product into several categories according to well-defined criteria (dimensions, weight, shape). Technical characteristics of SCA 5 are summarized in Table 4.

Table 4

Technical characteristics of SCA 5

\begin{tabular}{|l|c|}
\hline $\begin{array}{c}\text { Processing capacity, } \mathrm{kg} \cdot \mathrm{h}^{-1}: \\
\text { pre-cleaning } \\
\text { cleaning (selection) }\end{array}$ & 5000 \\
\hline Air flow rate fan $\mathrm{I}, \mathrm{m}^{3} \cdot \mathrm{min}^{-1}$ & 2500 \\
\hline Aspiration air flow $\mathrm{rate}$ fan $\mathrm{II}, \mathrm{m}^{3} \cdot \mathrm{min}^{-1}$ & 150 \\
\hline Overall dimensions: $\mathrm{LxWxH}, \mathrm{mm}$ & 120 \\
\hline Weight, $\mathrm{kg}$ & $5350 \times 1300 \times 3650$ \\
\hline
\end{tabular}

The seed mixture from the conveyor feed hopper is taken over by the buckets, conveyed by the belt and discharged into the separator funnel. From here, at the bottom of the funnel, at a flow rate regulated by a flow regulator, free falling seeds pass through the air jet produced by a centrifugal fan. The air flow is regulated by means of the deflector so as to ensure the flow rate for which seed cleaning can be performed and to obtain the degree of purity desired and the required capacity. Under the action of air currents, the seeds, depending on the specific weight, are thrown into the discharge hoppers. Those with higher specific weight are thrown to a smaller distance, while those with a lower specific weight are thrown further. Light impurities and dust are thrown away, into a channel, from where they are aspirated by the second centrifugal fan that tangentially inserts them into the cyclones from the cyclone battery. Here, due to the centrifugal force, they move on the inside of the cyclone tubes on a lower and lower trajectory and with less and less speed and, when this speed becomes zero, they fall into the dust collector due to gravitational force. From here the dust is extracted by means of the lock, evacuated and collected as waste. Seed collection is based on the degree of purification desired.

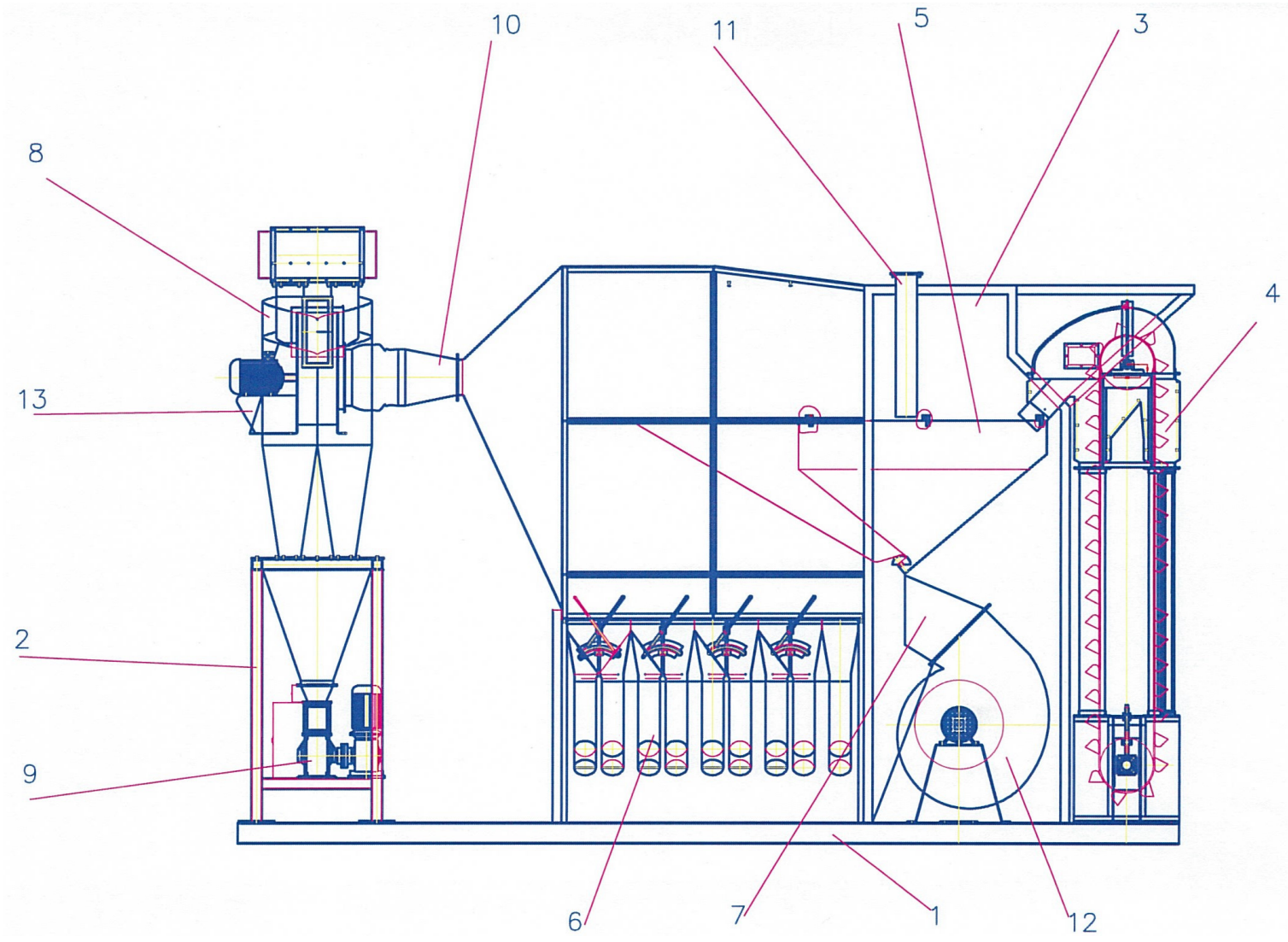

Fig. 1. SCA 5 Scheme of aeration cleaning separator: 1 - SCA 5 frame I; 2 - frame II; 3 - housing; 4 - feed conveyor; 5 - feed hopper; 6 - discharge hopper; 7 - fan coupling; 8 - cyclones battery; 9 - lock; 10 - connecting part; 11 - feed tube; 12,13 - centrifugal fans 
For storage in silos, where a high degree of purification is not required, only pre-cleaning is performed and if moving to a superior stage of the processing process is required, cleaning will be done. The cleaned seeds are collected in 5 fractions and the pre-cleaned ones in 4 fractions through the discharge hopper (pos.6), which is composed of a group of 9 smaller hoppers (Figure 2): 5 for collecting the cleaned seeds and 4 for collecting the pre-cleaned seeds. Passing from one position to another is done by an innovative diverter [15]. The diversion system ensures seed collection in the cleaned seed collecting hopper 8 or in the pre-cleaned seed collecting hopper 9 . The passage into the feed position of one of the two types of hoppers is made by deflecting the blade and passing the blade support through the guiding 10 .
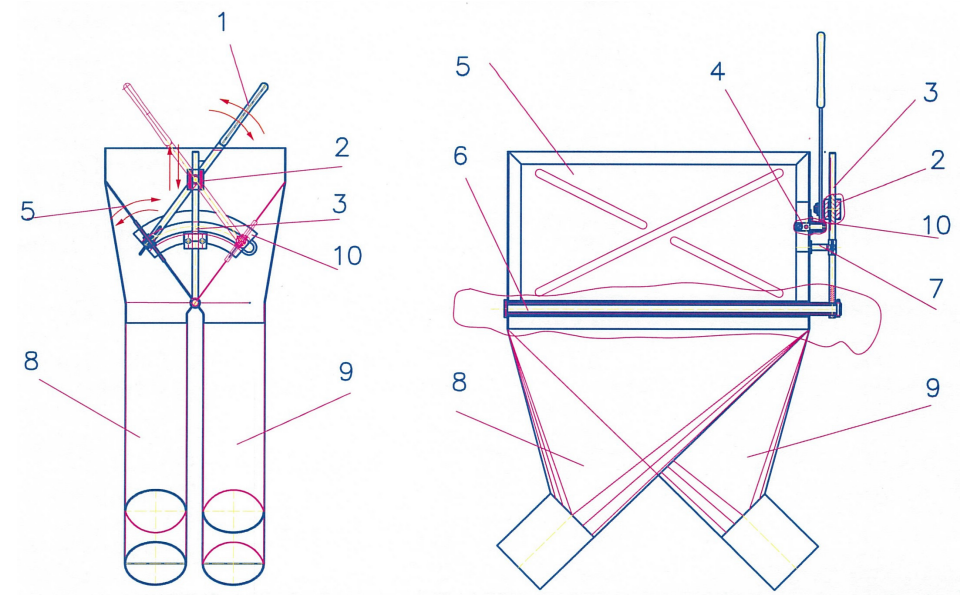

Fig. 2. Discharge hopper constructive scheme: 1 - hand lever; 2 - mobile piece; 3 - guiding support; 4 - blade support; 5 - blade; 6 - axle; 7 - fastening support; 8 - cleaned seeds hopper; 9 - pre-cleaned seeds hopper; 10 - guiding

The equipment allows for the best possible preparation of seeds for use as seed material, consumed or stored, at the level of the European standards in the field, observing the ecological requirements.

\section{Conclusions}

1. Based on the difference in aerodynamic attributes, the components of the cereal seed and industrial plant mass can be separated by entraining them in an air stream.

2. The aeration cleaning separator SCA 5 has the ability not only to clean, but also to sort seeds according to the specific weight in a single working cycle, respectively, separating into 9 distinct fractions by a single passage of the raw material through the machine, by means of an innovative seed collecting diverter. Also, the machine can clean and sort the groats and their products. The execution of the above-mentioned operations ensures obtaining seeds, which will present differentiated qualities, for sowing (if seed lots are processed), for proper storage and for a different valorization depending on the quality indices of the fraction.

3. The introduction to manufacturing of the aeration cleaning separator SCA 5 does not require special facilities, the economic agents specialized in the execution of these types of technical equipment have the technical facilities needed to assimilate it.

\section{Acknowledgements}

This paper was financed with the support of National Agency for Scientific Research and Innovation, Programme NUCLEU, no. 8N/09.03.2016, Act. Ad. no.2/2017, Project PN 16240204 "Technical-scientific foundation of an innovative technology for obtaining the seed material for the efficient establishment of agricultural crops".

\section{References}

[1] Costin I. Miller's Book, Technical Publishing House, Bucharest, Romania, 1999.

[2] Leonte M. Technologies and equipment in the milling industry - Grains preparing for grinding, Editura Millenium, Piatra - Neamţ, Romania, 2001, 565p. 
[3] Danciu I., Cereals cleaning, Publishing House of "Lucian Blaga" University, Sibiu, 2010.

[4] Didyh V.F. Improving the efficiency of drying agricultural plant materials: monograph, Lutsk, 2002, $165 \mathrm{p}$.

[5] Barsky E., Barsky M. Relationship between fractional separation curves and quantitative optimization criteria in the separation of pourable materials, Physical Separation in Science and Engineering, vol. 13, 2004, pp. 41-51.

[6] Geankoplis. Chr. Transport processes and separation process principles. Prentice Hall PTR; Fourth Edition, chapter 14, 2003, pp. 903-944;

[7] Căsăndroiu T. Primary processing and agricultural products storing, lithographed course, Politehnica University of Bucharest, 1993.

[8] Rus Fl. Separation operations in the food industry, Publishing Transylvania University of Braşov, Romania, 2001, pp. 75-101.

[9] Păun A., Pirnă I., Găgeanu P., Vlăduţ V. Increasing the added value of processed products in the milling industry by implementing a combined calibrator in wheat preparation technological scheme, INMATEH -Agricultural Engineering, vol. 36, no. 1/ 2012, Bucharest, Romania, 2012, pp. 63-68.

[10]Ciobanu V.G., A.L. Visan, Paun A, Nedelcu A. Comparative study regarding seed sorting equipment and the importance of implementing smart systems within the working process, JoKULL Journal 2015, Vol.64, No.9, pp.91-100.

[11]Zewdu A.D. Aerodynamic properties of the grain and straw material, Biosystems Engineering Journal, vol. 98, 2007, pp. $304-309$.

[12] Poon Eric K.W., Andrew S.H. Ooi, Matteo Giacobello, Raymond C.Z. Cohen, Hydrodynamic forces on a rotating sphere, International Journal of Heat and Fluid Flow, vol. 42, 2013, pp. 278288.

[13] Brăcăcescu C., Găgeanu I., Popescu S., Kemal C.S. Researches concerning impurities separation process from mass of cereal seeds using vibrating sieves in air flow currents, in Proceedings of 5th International Scientific Conference "Engineering for rural development" Jelgava, Letonia, 2016, pp.364-370.

[14] Găgeanu P., Păun A., Brăcăcescu C., Bunduchi G. Studies and researches regarding the performance of a cone-cylinder shape separator - aspirator for the separation of cereal grains by means of air currents in order to obtain ecological products INMATEH -Agricultural Engineering, vol. 18, no. 3/ 2006, Bucharest, Romania, pp. 91-100.

[15] Găgeanu P. Patent application-Seed collecting diverter for aeration cleaning separator. A00973/2017. 